\title{
PROVOCAÇÕES PÓS-HUMANISTAS À TEOLOGIA CRISTÃ
}

\author{
Post-Humanistic Provocations to Christian Theology
}

Abdruschim Schaeffer Rocha *

RESUMO: O artigo visa discutir algumas provocações pós-humanistas à Teologia cristã, considerada em sua vertente mais progressista. Nesse sentido, desconsidera as posições fundamentalistas de determinados segmentos do Cristianismo e da Teologia cristã, fortemente marcados pelo dualismo. Parte do pressuposto de que, mesmo considerando suas melhores reflexões antropológicas, a Teologia Cristã ainda assim se sente interpelada e desafiada pelas propostas pós-humanistas. Apresenta o pós-humanismo em suas vertentes crítica e especulativa, destacando seus principais pressupostos e possibilidades. Finalmente, propõe três provocações pós-humanistas à Teologia cristã, quais sejam: a questão da integralidade do ser humano; a questão da promoção da vida e a questão da mudança comportamental.

PALAVRAS-CHAVE: Humanismo. Pós-humanismo. Transumanismo. Teologia. Biotecnologias.

ABSTRACT: The article aims to discuss some post-humanistic provocations to Christian Theology, in its most progressive aspect. In this sense, it chooses to ignore the fundamentalist positions of certain branches of Christianity and Christian Theology, strongly influenced by dualism. It starts from the assumption that even when considering its best anthropological reflections, Christian Theology is still addressed and challenged by post-humanistic proposals. Then, it presents the critical and speculative aspects of post-humanism, highlighting its main assumptions and possibilities. Finally, it proposes three post-humanistic provocations to Christian Theology, namely: the question of the integrity of the human being, the issue of the promotion of life and that of behavioral change.

KEYWORDS: Humanism. Post-humanism. Transhumanism. Theology. Biotechnology.

* Faculdade Unida de Vitória, Vitória, ES, Brasil. 


\section{Introdução}

$\mathrm{F}^{\mathrm{m}}$ alguns aspectos, o século XX se apresentou como uma espécie de di乙visor de águas no contexto do mundo ocidental. Fomos colocados frente a frente com o horror de duas grandes guerras mundiais, do holocausto nazista (e de tantos outros) e com mudanças geopolíticas que colocaram fim ao otimismo exacerbado da Modernidade. O projeto moderno também se mostrou insuficiente à medida que se caminhava em direção a uma concepção de linguagem que deixou de figurar o mundo e relativizou-se ao ponto de mostrar muito mais a realidade humana, historicamente situada, do que a realidade objetiva. Essa perspectiva pós-metafísica teve a força de mostrar o mundo como um grande texto, diante do qual o ser humano se revelaria como ontologicamente intérprete. Assistimos o crescente desinteresse pelo autor, a derrocada do estruturalismo e a paulatina ascensão de perspectivas semióticas do mundo que priorizam o leitor e sua recepção da obra. Assistimos o fim do humanismo moderno e a ascensão de uma nova espécie de humanismo - menos utópico porquanto mais consciente das limitações humanas -, que de modo geral se fez sentir nas Ciências Humanas e, de modo particular, na Teologia, tanto em sua vertente católica quanto protestante.

Mas, esse também foi o século da convergência do computador e das telecomunicações, que possibilitou o desenvolvimento vertiginoso das tecnologias digitais, capaz de efetuar o armazenamento e recuperação de informações de forma ampla e quase irrestrita. Nesse turbilhão de mudanças, ficamos não apenas mais rodeados de coisas do que de pessoas, com muito bem diagnosticou Jean Baudrillard (BAUDRILLARD, 2008), como também testemunhamos uma interface cada vez maior entre seres humanos e máquinas, num contexto de intensa troca de informações. Não se sabe ao certo para onde o mundo está caminhando, mas de uma coisa se pode ter certeza: a influência da tecnologia digital, e tudo o que ela carreia, continuará a crescer e a alterar significativamente o modo como compreendemos tempo e espaço, o modo como nos comunicamos e nos expressamos, o modo como ensinamos e aprendemos, o modo como nos relacionamos uns com os outros e o modo como interpretamos e interagimos com o mundo à nossa volta. Ou seja, a revolução tecnológica pela qual passamos é psíquica, cultural e socialmente sem precedentes, com repercussões, inclusive, no âmbito da religião. Não se pode negar, portanto, que tais revoluções tiveram e continuam tendo um impacto antropológico gigantesco. Que tipo de ser humano se insinua para um futuro que parece cada vez mais presente? Para além das mudanças na concepção de corpo, também experimentadas ao longo do século XX, qual será, afinal, o limite para tais transformações?

O presente artigo pretende levantar algumas das principais provocações que tais mudanças, sob o signo do pós-humanismo, sugerem à Teologia 
Cristã. Para tanto, divide-se em duas partes: a primeira busca apresentar os principais elementos que formam a agenda pós-humanista, destacando em que sentido o pós-humanismo se distancia do humanismo, em sua mais atual e relevante versão, e as questões que são próprias de um pós-humanismo crítico, bem como de sua vertente mais especulativa. A segunda parte dedica-se a apresentar três provocações do pós-humanismo à Teologia Cristã, em sua versão mais progressista.

\section{Pós-humanismo e sua agenda}

Inscrito no contexto dos assim chamados "pós", como se pode perceber em movimentos como pós-modernidade, pós-colonialismo, pós-secularidade, pós-industrialismo, entre outros, o pós-humanismo também se situa entre a continuidade e a ruptura. É nesse sentido que se apresenta em relação ao humanismo, tanto em sua vertente crítica quanto em sua vertente especulativa, como veremos.

\subsection{Do humanismo ao pós-humanismo}

O humanismo tão celebrado na Modernidade, relido na Contemporaneidade e tão reverenciado pelas Ciências Humanas, encontra-se agora seriamente questionado. Os pressupostos sobre os quais se erigiu, tais como a autonomia, a liberdade e a racionalidade - elementos que também engendraram a Modernidade e se constituíram nos fundamentos para a construção do sujeito moderno - foram colocados sob suspeita e mostraram-se insuficientes diante dos efeitos históricos que se seguiram a esse projeto. Além dos vários autores que questionaram a força do sujeito moderno, tais como Nietzsche, Marx e Freud, ${ }^{1}$ uma série de acontecimentos consolidou essa suspeita: duas guerras mundiais, holocaustos tais como o nazista e o ameríndio, mudanças geopolíticas e a dificuldade de a ciência resolver os principais problemas da humanidade contam-se entre os mais importantes acontecimentos históricos que mostraram a fragilidade do sujeito moderno.

Mas, isso não significou o sepultamento do humanismo, apenas abriu espaço para sua reinvenção sobre novos pilares. Habermas, por exemplo, criticou o sujeito moderno, demonstrando a fragilidade dos conceitos de autonomia, liberdade e racionalidade, tais como foram compreendidos no contexto da Modernidade (HABERMAS, 1989). Diante da ideia de um sujeito autônomo que se pressupõe capaz de construir sua própria história e, ao

${ }^{1}$ Paul Ricoeur cunhou a expressão "mestres da suspeita" para destacar esse papel de crítica ao sujeito moderno, levada à efeito por Nietzsche, Marx e Freud (RICOEUR, Paul. Da Interpretação: ensaio sobre Freud. Rio de Janeiro: Imago Editora, 1977). 
fazê-lo, também constrói a história da humanidade, Habermas denuncia as bases metafísicas dessa concepção de história que a concebe como densa, organizada e estruturada na direção de um progresso permanente. Para ele, a Modernidade logo descobrirá que o sujeito da história, ao contrário, vincula-se a estruturas que fogem de seu controle e isso implica no fim de uma história universal homogênea e linear. Na perspectiva habermasiana, a liberdade moderna, igualmente concebida numa ótica metafísica, é mal articulada, na medida em que não deriva de uma conquista histórica e intersubjetiva - é especialmente significativa aqui a crítica psicanalítica a esse respeito, afinal, nela deflagra-se a condição ilusória dessa liberdade e revela-se a incapacidade do sujeito em perceber as forças irracionais que subjazem ao seu comportamento racional. $\mathrm{O}$ eu moderno, enquanto pura consciência, pura razão, também é criticado por Habermas. Para ele, a ideia de uma razão que se aperfeiçoa na medida em que se liberta das paixões, dos sentimentos, de supostos interesses irracionais e do próprio corpo, também deve ser superada. É nesse sentido que Habermas, diante da insuficiência das bases sobre as quais se constrói o sujeito moderno, proporá o conceito de "sujeito comunicativo", segundo o qual subordina-se a dimensão epistêmica da pessoa às dimensões prática e comunicativa (HABERMAS, 1988).

O filósofo francês Luc Ferry, por sua vez, destaca a insuficiência da proposta moderna, que preconizava a fundamentação do mundo sobre a razão, a subjetividade e os direitos do humanismo republicano. Para ele, a revolução da subjetividade, tal como fora proposta por Descartes e se estendeu pelo Século das Luzes, trata-se da própria revolução humanista. Esse humanismo fundará a salvação, não mais no Cosmo ou em Deus, mas no próprio homem. No humanismo moderno, a liberdade humana ou sua capacidade de subtrair-se das determinações naturais e das tradições histórico-sociais, é o que distingue o homem de todas as outras criaturas. Para Ferry,

[O homem] não é definido por uma "natureza" que lhe seria própria, nem sequer por uma história da qual seria prisioneiro, mas "cria-se", está em permanente criação através do progresso das ciências e das artes, através da conquista de uma autonomia sempre maior, através do domínio sempre crescente de uma história por vezes revolucionária, que lhe dão os meios de alcançar a busca da felicidade [...] (2013, p. 37).

Ferry destaca que as filosofias do passado não são mais suficientes para fornecer sentido. Ele elenca quatro grandes princípios de sentido, quatro definições de vida boa, de salvação que foram determinantes ao longo da civilização ocidental: o princípio cosmológico; o princípio teológico; o princípio humanista e o princípio da desconstrução (FERRY, 2013, p. 33-41). O filósofo francês analisa o esgotamento de todas essas fontes de sentido e sugere uma nova: o princípio do amor. Esse seria o quinto princípio de sentido, ou a quinta resposta à questão da vida boa. Ou seja, o 
que ele propõe é um segundo humanismo, “[...] que se segue à época da desconstrução do primeiro humanismo" (FERRY, 2013, p. 64).

Para Ferry, o amor liga-se estreitamente com a ideia de sacrifício, afinal, este sempre indica aquilo que de fato consideramos essencial e, portanto, $\mathrm{o}$ que "dá sentido e valor ao que pensamos, fazemos, procuramos". Por isso, o sentido sempre se estabelece em relação ao sagrado e, historicamente, as figuras do sagrado estão ligadas ao sentido de existência. O sagrado, então, tende a encarnar na própria humanidade e é por isso que, para ele, trata-se da consolidação de um novo humanismo (FERRY, 2012, p. 18-19). A proposta de Ferry, que parte de sua análise do contexto ocidental europeu, é que a vida amorosa de pessoas comuns, em seu cotidiano, substitua, portanto, os ideais políticos e religiosos que se constituíram nas fontes de sentido no passado. Portanto, a proposta é de uma sacralização do amor, uma espiritualidade laica. O amor, então, deveria ser a nova fonte de sentido, com força suficiente para suscitar uma valorização maior das pessoas em relação às instituições.

Muitos outros exemplos poderiam ser dados no sentido de mostrar a tendência no contexto da qual estão pensando os muitos intelectuais que representam uma vertente mais progressista daquelas reflexões que buscam compreender o ser humano e suas relações com o outro, com a cultura, com o conhecimento, com a vida, etc. Entretanto, apesar desse humanismo progressista, o número de autores que propõem uma era pós-humana também é cada vez maior. Nessa perspectiva, não se trataria mais de reformar o humanismo, como talvez proponha Habermas e Luc Ferry, mas de subvertê-lo completamente.

\subsection{O fenômeno pós-humano em sua vertente crítica}

Rumores de um pós-humanismo já ganham espaço na literatura desde a década de 1980. O "Manifesto Ciborgue: Ciência, Tecnologia e Feminismo-socialista ao Final do Século XX", de Donna Haraway, ficou mundialmente conhecido, sobretudo por sua proposta de uma leitura feminista e progressista do mito do ciborgue (HARAWAY, 1985, p. 149-82). Nesse manifesto, que trouxe enormes consequências para as feministas norte-americanas, Haraway trata das transformações do corpo por meio de tecnologias, discussão que de lá para cá tem se adensado cada vez mais. A ideia do ciborgue, proposta por Haraway, na medida em que questiona as tradicionais dicotomias ocidentais, tais como as relações natureza-cultura, organismo-máquina, mente-corpo ou mesmo masculino-feminino - que também serviam de plataforma para a manutenção do patriarcado -, inaugura a problematização de questões que remetem à relação do humano com a tecnologia, mas, além disso, à própria constituição ontológica do humano. O manifesto de Haraway sugere que num mundo habitado por ciborgues, ou seja, por seres híbridos em quem convergem o orgânico e o 
tecnológico, as diferenças simplesmente não fazem mais sentido. E, nessa perspectiva, o fim da diferença sexual marca o fim de todas as outras. Para nos utilizarmos aqui das expressões de Luc Ferry, é possível dizer que a "vida boa" ou a "salvação", nesse caso, consistiriam na anulação de todas as diferenças, numa espécie de retorno dionisíaco do múltiplo à igualdade fundamental de tudo. A possibilidade de corpos pós-humanos significa não apenas desestabilizar as velhas identidades, construídas a partir de orientações hierárquicas e valores masculinos, mas, também, questiona os limites disso que chamamos de humano.

Conquanto tenha popularizado o termo "ciborgue", não foi Haraway quem o cunhou. A expressão foi criada por Clynes e Nathan Kline, em 1960, proposta a partir da junção de cyb (ernetic) e org (anism). Eles criaram a palavra inspirados no experimento realizado com o rato de Rockland, que consistia na utilização de uma bomba que injetava em seu corpo substâncias químicas em doses controladas. A expressão foi utilizada por eles para descrever o "homem ampliado", ou seja, um ser humano mais bem adaptado às viagens espaciais, já que se postulava um coração que fosse controlado por injeções de anfetaminas e uma "célula energética inversa", alimentada por energia nuclear, em substituição aos pulmões. A partir de então, a ideia de um ser humano ampliado pelas tecnologias ganhou espaço, inclusive no cinema, estabelecendo o ambiente fértil ideal para a repercussão do manifesto de Haraway (SANTAELLA, 2003, p. 187-189).

Segundo Lucia Santaella, na tentativa de se consolidar a ideia de um pós-humano caracterizado pela mutação dos corpos resultante da simbiose entre o ser humano e as próteses tecnológicas, muitos são os termos alternativos a "ciborgue" que têm sido propostos. Além do termo pós-humano, outras possibilidades incluem: "corpo protético"; "pós-biológico"; "pós-orgânico", etc. Este último, por exemplo, é usado numa importante obra que versa sobre esse hibridismo entre o humano e o tecnológico, escrita por Paula Sibilia: "O Homem Pós-orgânico. Corpo, Subjetividade e Tecnologias Digitais" (SIBILIA, 2002). Para Sibilia, conquanto a junção entre ser humano e tecnologia tenha sempre existido, vivemos um tempo no qual esse tema tem sido cada vez mais aprofundado e problematizado. Segundo Sibilia, no horizonte da digitalização universal, surge uma possibilidade inusitada:

[...] o corpo humano, em sua antiga configuração biológica, estaria se tornando obsoleto. Intimidados pelas pressões de um meio ambiente amalgamado com o artifício, os corpos contemporâneos não conseguem fugir das tiranias (e das delícias) do upgrade. Um novo imperativo é internalizado, num jogo espiralado que mistura prazeres, saberes e poderes: o desejo de atingir a compatibilidade total com o tecnocosmos digitalizado. Para efetivar tal sonho é necessário recorrer à atualização tecnológica permanente: impõem-se, assim, os rituais do auto-upgrade cotidiano (2002, p. 13).

Além de Sibilia e outros tantos pesquisadores, a própria Santaella tem proposto um termo alternativo: desde 1998 tem trabalhado com o termo 
"biocibernético", como pode ser claramente percebido no próprio título de uma de suas obras: "O Corpo Biocibernético Revisitado" (2004). Embora utilize esse termo num sentido similar ao de ciborgue, sua preferência se justifica por dois motivos: em primeiro lugar, segundo ela, o sentido de "bio" é mais abrangente do que "org"; em segundo lugar, "biocibernético" explicita melhor a hibridização do biológico e do cibernético, além de ser uma expressão que culturalmente ainda não foi sobrecarregada de conotações triunfalistas ou sombrias, próprias do mundo cinematográfico (2004, p. 53-64).

Mas, o tema do pós-humano não se restringe às questões relativas ao corpo humano. Segundo Santaella, o tema tem sido discutido atualmente em várias frentes. Nesse sentido, além da escala do corpo, no mínimo outras três escalas se destacam: a escala da inteligência humana, cujo principal problema em pauta é o da inteligência coletiva; a escala dos ambientes, que estão ficando cada vez mais inteligentes, tais como residências inteligentes, cidades inteligentes, agricultura inteligente, etc.; a escala da biosfera, cuja principal temática gira em torno da nova era biológica que vem sendo chamada de Antropoceno (ARTAXO, 2014).

Robert Pepperell, em sua obra A Condição Pós-Humana (1995), destaca que a expressão "pós-humano" pode ser utilizada em vários sentidos. Pepperell destaca três sentidos, que nos são úteis para compreendermos, de modo geral, as matrizes da discussão a partir das quais as várias possibilidades de uso da expressão se colocam. Em primeiro lugar, a expressão indicaria o esgotamento e fim do humanismo (tanto o moderno quanto o pós-moderno), no sentido de que o pós-humano significa o que vem "depois do humanismo". Trata-se, inclusive, de um movimento posterior às vertentes mais progressistas do humanismo, como, por exemplo, a proposta de Ferry, vista em 1.1. Em segundo lugar, o "pós-humano" indica as profundas transformações que estão alterando nossa visão daquilo que constitui o humano. Ser humano, nesse sentido, não significará mais aquilo que até aqui significou, nem tampouco se aproximará dos antigos conceitos, o que indica uma perspectiva não apenas de ultrapassamento, mas de rompimento com o paradigma humanista. Em terceiro lugar, o "pós-humano" aponta para uma convergência dos organismos com a tecnologia até o ponto de não serem mais distinguíveis. Na perspectiva de Pepperell, as tecnologias pós-humanas incluem a realidade virtual, comunicação global, proteica e nanotecnologia, redes neurais, algoritmos genéticos, manipulação genética e vida artificial.

A condição pós-humana e as implicações da revolução biotecnológica colocam para a humanidade enormes dilemas éticos que não podem ser ignorados. Por outro lado, há discursos que acreditam ser improcedente a separação entre a evolução biológica e a evolução tecnológica. Para Merlim Donald, por exemplo, ambas as evoluções são inseparáveis (1991). Em 
geral, quem defende a possibilidade do pós-humano - numa perspectiva crítica e antropologicamente mais refinada -, parte do pressuposto de que na escala da evolução, o domínio de certas técnicas por parte dos nossos ancestrais hominídeos e o aperfeiçoamento cada vez maior do artifício para a manutenção da vida é o que, definitivamente, separou o ser humano da cadeia natural dos outros seres. Lascar a pedra e dominar o fogo, ou mesmo utilizar-se de ferramentas para se defender ou para comer, contam-se entre as primeiras tecnologias que foram dominadas pelos seres humanos, e o desenvolvimento dessas e de outras tantas é o que garantiu a preservação da espécie humana perante as demais espécies. O horizonte tecnocientífico que se coloca seria, então, apenas mais um estágio, um ciclo evolutivo do Sapiens sapiens (que, supostamente, seria tecnológico por natureza). Visto sob essa ótica, é como se pudéssemos afirmar que a tecnologia é que nos possibilitou a condição de ser humano. Nesse sentido, o pós-humanismo não seria apenas resultado do sonho humano de onipotência, mas estaria inscrito no programa genético da espécie humana, que certamente não deveria ser visto em sua perspectiva determinista, mas no horizonte da imprevisibilidade, já que incorpora o acaso e imponderável. Ou seja, a paradoxalidade do ser humano, que o admite como natural e ao mesmo tempo artificial, estaria previsto no âmbito de possibilidades da evolução humana. Portanto, embora as transformações humanas pela tecnologia tenham se tornado visíveis mais recentemente, sobretudo, após a revolução industrial e digital, toda a história do ser humano demonstra que, enquanto ser que nasce inacabado, seria ele indissociavelmente ligado à tecnologia.

Esse pós-humanismo, que poderíamos classificar como crítico, conta, por outro lado, com oposições de vários lados. Normalmente, os críticos do pós-humanismo são nomeados como bioconservadores. Em geral, são teóricos de várias áreas, que nutrem discordâncias, sobretudo, no campo antropológico. Muitas dessas discordâncias são geradas a partir de concepções que se ancoram no pressuposto de que a humanidade se constrói por elementos biológicos e culturais, qualquer que seja o conceito de humano que se nutra. Ou seja, nesse sentido, o tecnológico - que até nos grandes "mestres da suspeita", Marx, Nietzsche e Freud, foi ignorado - se apresenta como uma excrecência desse misto de natural e cultural. É como se a ideia de humano necessariamente exigisse o pressuposto de uma essência imutável e sacralizável, pensamento que paulatinamente vem se desmistificando desde o fim da Idade Média, com as primeiras dissecações de cadáveres (MANDRESSI, 2012, p. 411-440), passando pela prática de autópsias realizada no contexto da medicina moderna, a partir das quais o corpo morto se tornou tão importante quanto o corpo vivo (FAURE, 2012, p. 17-26), até o século XXI, com as novas percepções sobre o corpo adoecido que se constroem diante das mais diversas possibilidades de intervenção tecnológica (MOULIN, 2011, p. 15-82). O pós-humanismo em sua vertente crítica, portanto, procura problematizar essa ideia de um ser humano como essência imutável. 


\subsection{O fenômeno do pós-humanismo em sua vertente especulativa}

O que se conhece hoje como pós-humanismo ou transumanismo se caracteriza por ser uma espécie de utopia (mas que paulatinamente vai se delineando como um novo campo do saber) que tem por objetivo fazer convergir diversas disciplinas de ponta com vistas ao incremento do ser humano. Ou seja, busca-se melhorar a performance dos seres humanos em áreas como, por exemplo, a memória, a audição, a visão, performances intelectuais, longevidade, etc., a partir da intercessão entre quatro novos grupos de tecnologias: nanotecnologias, biotecnologias, tecnologias da informação e ciências cognitivas, normalmente agrupadas sob a sigla $\mathrm{NBIC}^{2}$ (LACROIX, 2014).

O transumanismo ou, como alguns nomeiam, o pós-humanismo ilusionista, diz respeito a um tipo especulativo e pouco crítico de pós-humanismo. ${ }^{3}$ Uma de suas principais características é a ousadia nas propostas pós-humanistas, como, por exemplo, a superação absoluta dos limites biológicos com vistas à libertação do processo de adoecimento, ao adiamento do envelhecimento ou - mais radical ainda - às promessas de imortalidade. Empresas e Centros de Pesquisa ao redor do mundo começam a envidar esforços no sentido de elevar a humanidade a um novo patamar biotecnológico e, assim, contribuir para esse intento. Em vários dos segmentos que se agrupam em torno da NBIC já existem pesquisas significativas que tornam o horizonte transumanista extremamente fértil, no qual se percebe que a zona entre a ficção e a realidade se torna cada vez mais tênue.

A título de exemplo, pode-se dizer que, em termos de nanotecnologia, já existem várias empresas no mundo e no Brasil investindo em produtos que prometem impactar de forma significativa a maioria das indústrias. As nanotecnologias têm sido usadas na melhoria dos sistemas de construção, no setor matalmecânico, na cerâmica, nos cosméticos, etc., afinal, tratam-se de tecnologias que possibilitam a fabricação de produtos mais duráveis, seguros e inteligentes. Atualmente, essas tecnologias já têm sido usadas em plásticos, calçados infantis, roupas, hidratantes, no tratamento de água, em couros, combustíveis, no aprimoramento de próteses, etc. Mas, já se fala na possibilidade de criação de nanodispositivos para a

\footnotetext{
${ }^{2}$ A revolução tecnológica pressupõe 4 pilares: Nano (N), Bio (B), Info (I) e Cogno (C), a partir dos quais o pós-humano se estrutura.

${ }^{3}$ Em certo sentido, a expressão "transumanismo" pode ser compreendida como sinônimo de pós-humanismo. Entretanto, o termo pode designar, também, uma expressão mais radical do pós-humanismo. A essa tendência mais especulativa, Paulo Sibilia associa a expressão "impulsos neognósticos" (SIBILIA, 2002, p. 91). Para uma melhor compreensão da crítica feita às vertentes mais radicais do pós-humanismo, ver o artigo de João Manoel Duque "Utopias neognósticas do pós-humano na cibercultura: para uma leitura filosófico-teológica" (DUQUE, 2016).
} 
regeneração de tecidos, e aí, obviamente, não faltam discursos que veem nisso a possibilidade da imortalidade humana ${ }^{4}$.

Alexandre Quaresma, autor dos livros "Nanocaos e a Responsabilidade Global" (2006) e "Nanotecnologias: Zênite ou Nadir?" (2010), afirma a existência de centros de criogenia, nos quais se preservam cérebros e corpos de pessoas ricas que estão congelados neste momento à espera de tecnologia futura capaz de reengendrar a vida a fim de que possam retornar. $\mathrm{O}$ site Futurism registrou em 2017 o que dizem ser o primeiro caso de uma mulher na China congelada criogenicamente. Zhan Wenlian morreu aos 49 anos de câncer de pulmão e seu marido ofereceu-a para ser submetida ao procedimento criogênico. Tanto ele quanto sua falecida esposa desejavam doar o corpo à ciência. $O$ projeto que tornou isso possível é um esforço colaborativo do Yinfeng Biological Group, Qilu Hospital Shandong University e de consultores da Alcor Life Extension Foundation, uma empresa de criogenia sem fins lucrativos com sede nos Estados Unidos. ${ }^{5}$

Outras promessas inscritas no futuro transumanista defendem a ideia de uma extinção da raça humana, tal como a conhecemos hoje, e o advento de uma raça pós-humana, feita de ciborgues e toda a sorte de seres híbridos. Também incluem o aumento da expectativa de vida para algo superior a 500 anos, a multiplicação das capacidades cognitivas, o controle total dos sentidos e das emoções (GONZÁLEZ MELADO, 2010, p. 206), além da possibilidade de se corrigir os genes, o que significaria não apenas evitar doenças futuras, mas, também, determinar a cor dos olhos, do cabelo, ou mesmo o sexo. Percebe-se que, seja interna ou externamente, o ser humano é cada vez mais plástico ou "líquido" (para nos utilizarmos aqui de uma metáfora de Zygmunt Bauman). Para Couto, é antigo o anseio de potencializar o corpo humano no desejo de se superar a vulnerabilidade que lhe é inerente. Da mitologia aos nossos dias, adensam-se cada vez mais os esforços para se superar a morte (COUTO SOUZA, 2009, p. 46-48).

Muitos são os exemplos de seguimentos da NBIC que poderiam ser usados, mas o que se quer destacar aqui são as perspectivas utópicas que nascem desse conglomerado de descobertas biotecnológicas. Erick Felinto, nesse sentido, destaca o pós-humanismo como uma das mais relevantes narrativas digitais com as quais nos defrontamos atualmente, o que demonstra a amplitude dessa revolução. Segundo ele, temas como os da transcendência, do espiritualismo tecnológico, da informatização do real e da expectação futurista utópica, constituem-se em alguns dos

\footnotetext{
${ }^{4}$ DIÁRIO CATARINENSE. Revolução microscópica: indústrias de diversos setores de Santa Catarina investem em nanotecnologia. Disponível em: <https://bit.ly/2Nfg5Pf $>$. Acesso em: 20 jun.2018.

${ }^{5}$ FUTURISM. For The First Time Ever, A Woman in China Was Cryogenically Frozen: But is the procedure actually viable? Here's what you need to know. Disponível em: $\langle$ https://bit.ly/2vQgwtB $>$. Acesso em: 20 jun. 2018.
} 
principais elementos dessa narrativa (2006, p. 119). Como se trata de uma narrativa, ou seja, de uma linguagem densa de sentido que se constrói a partir de certa perspectiva - uma espécie de "vingança" humana contra a mortalidade -, capaz de possibilitar a criação de "novos mundos", e que vai muito além da tecnologia e da biologia, não se pode negar que haja dimensões antropológicas e filosóficas que surgem no contexto da expressão. Também por isso, verifica-se cada vez mais o surgimento de espiritualidades transumanistas, que veem nessa proposta a possibilidade de re-ligações transcendentais de todo tipo. Nesse sentido, é digno de nota que Felinto distinga entre um pós-humanismo popularizado na Internet e o que chama de pós-humanismo crítico, perspectiva esta que mereceria a atenção devida e a consequente reflexão séria.

Portanto, se considerarmos o fato de que a Internet se constitui numa plataforma indispensável para a efetivação das possibilidades pós-humanistas, além de considerar o leque de positividades que ela apresenta, também é preciso reconhecê-la como um terreno fértil para a proliferação de toda a sorte de especulações com relação ao tema. Dentre tantas interpretações especulativas, não faltam tentativas de apropriação dessas tendências por parte de movimentos místicos e espiritualistas, como, por exemplo, os Extropians, seita radical que professa uma filosofia transumanista, a partir da qual pressupõe que os limites humanos serão resolvidos com a passagem para a condição transumana. ${ }^{6}$ João Manuel Duque explicita:

Uma proposta bem mais explícita e radical é a que foi apresentada pelo grupo dos denominados Extropianos. Max More é o seu principal ideólogo, tendo fundado, juntamente com Tom Morrow em 1991, o Extropy Institute. A sua ideia fundamental é que o mundo, sobretudo a humanidade, se encontram em processo de extropia ou expansão das suas capacidades, e não de entropia. Nesse processo evolutivo, ganha especial lugar a superação do ser humano - ou a sua transformação num ser pós-humano. O principal factor dessa transformação é a superação dos limites do tempo e do espaço, provocados pela corporeidade do humano. Nesse sentido, a tecnologia possibilita o decisivo passo para o pós-humano, na medida em que permite, entre outros modos pelo processo de virtualização, o abandono das limitações provocadas pelo corpo. Assim atinge-se a liberdade sonhada em todos os tempos - liberdade de estruturas, de instituições, de leis, do tempo, do espaço, de si mesmo enquanto corpo pesado, etc. (2016, p. 163-182 [172-173]).

O Extropy Institute considera realizada a sua missão, independentemente da transformação ou não dos corpos, seja por implante ou multiplicação, afinal, a realização dessa mesma utopia não necessitaria desses processos, mas, supostamente poderia ser realizada pelo ciberespaço. A prevalência do ciberespaço, nesse sentido, inauguraria uma espécie de "era do espírito".

Mas, embora as manifestações ousadas e até exageradas existam, não se pode negar que haja muito estudo sério e milhões de dólares investidos

${ }^{6}$ EXTROPY INSTITUTE. Disponível em: <www.extropy.org>. Acesso em: 09 out. 2018. 
em pesquisas ao redor do mundo, no sentido de tornar possível aquilo que hoje existe apenas no plano teórico ou parcialmente realizado.

\section{Provocações pós-humanistas à Teologia Cristã}

O diálogo sempre foi uma necessidade constitutiva da Teologia desde o seu nascedouro. Seu confronto com a Filosofia, que se deu tanto com as grandes correntes do pensamento grego antigo quanto com as inúmeras vertentes do pensamento moderno e contemporâneo, bem como suas querelas com a ciência moderna, que exigiram uma ampliação das possibilidades de se produzir conhecimento sobre o mundo, tiveram a força de estabelecer sua identidade. Ou seja, fazem parte do modo-de-ser da Teologia - e do próprio Cristianismo - essas relações que a impulsionam sempre para além de si mesma, tornando a fronteira um lugar privilegiado de reflexão. Embora muitos ainda tendam a pensá-la como uma entidade autocontida, que supostamente deveria ser vista a partir de si mesma, não se pode negar que haja uma chamada ao novo que demanda contribuições do outro e exige uma superação de quaisquer reações apologéticas. Quanto a isso, é significativa a assertiva de Torres Queiruga:

A reação cristã só será crível se conseguir acolher o que de genuíno há nestas chamadas do novo e de mostrar-se capaz de integrá-lo, dinamizá-lo e enriquecê-lo desde seu projeto específico. Condição indispensável para isso é a de se deixar questionar honestamente e, renovando o contato com suas raízes, mostrar-se dispostos à mudança e à renovação: à "conversão" (2003, p. 117).

Como muito bem pontua Torres Queiruga, essa vocação ao novo exige que se deixe questionar honestamente. É com essa disposição que a Teologia é convocada a se posicionar diante dos desafios que se colocam pelo pós-humanismo. Propositadamente deixamos de lado as reações e posicionamentos mais afeitos a uma abordagem fundamentalista das questões pós-humanistas, pois, diante de tanta produção intelectual sobre o fundamentalismo, ficam mais ou menos entrevistas suas respostas e as possíveis críticas que aí caberiam. Em vez disso, o propósito do presente artigo é o de refletir as provocações pós-humanistas à Teologia em sua vertente mais progressista. Ou seja, o pressuposto aqui é o de que, mesmo quando consideramos os posicionamentos antropológicos mais progressistas, ainda assim a Teologia se vê confrontada com tais questões, fato que indica as proporções dessa eventual mudança de paradigma. Diante de tantas possíveis provocações, gostaríamos de destacar apenas três, que se referem à pauta mais progressista do Cristianismo e/ou da Teologia cristã: 1) a questão da integralidade do ser humano; 2) a questão da promoção da vida; e 3) a questão da mudança comportamental humana. 


\subsection{A questão da integralidade do ser humano}

Infelizmente, ainda estamos lidando com pressupostos religiosos e, automaticamente, com teologias extremamente dualistas. Uma visão dualista do corpo, normalmente expressa na relação compartimentalizada corpo-alma, em grande medida ainda representa o modo a partir do qual se vive o Cristianismo ou se faz Teologia, razão pela qual é possível afirmar que ainda somos significativamente afetados por essa visão metafísica do mundo. Isso mostra a força e influência da filosofia platônica na construção da Teologia cristã, sobretudo em sua vertente ocidental. ${ }^{7}$

Somente muito recentemente alguns teólogos começaram a buscar alternativas não dualistas para se pensar uma antropologia teológica. Normalmente, são teólogos que se acostumaram a pensar sua teologia na fronteira com outras áreas do conhecimento, muitos dos quais influenciados pelas propostas que se seguiram à chamada Virada Linguística. ${ }^{8}$ Em geral, essas propostas mais progressistas tendem a postular uma antropologia na qual o ser humano, individualmente pensado, é visto como sendo o seu próprio corpo. De várias áreas, sobretudo das Ciências Humanas, emergem reflexões que subsidiam essa teologia de corte não dualista. Esse grupo de teóricos provenientes de áreas afins inclui, por exemplo, antropólogos como Marcel Mauss e David LeBreton (antropologia e sociologia do corpo); filósofos como Maurice Merleau-Ponty e Michel Henry (fenomenologia da percepção e do corpo); também filósofos da tradição pragmatista, como o norte americano Donald Davidson, que propõe aquilo que denomina de "monismo anômalo", além de muitos outros.

Portanto, todas as teologias que se constroem no diálogo com essas e tantas outras contribuições teóricas derivadas de áreas afins à Teologia são o que temos hoje de mais progressista em termos de concepção de ser humano. Mas, quando dizemos que isso é o mais progressista que temos em termos de teologia do corpo, é bom reafirmar que dispomos de poucas reflexões que se colocam nessa direção. Ou seja, além de ainda não termos resolvido completamente o problema do dualismo, sobretudo em sua vertente platônico-cartesiana, já se faz necessário considerar todas as questões levantadas pelo pós-humanismo. Em outras palavras: de modo geral, ainda não se chegou numa condição de plena humanização da Teologia e já somos confrontados com sua suposta pós-humanização. Isso mostra, também de modo geral, como a Teologia parece ser lenta quando se trata de estabelecer um diálogo com o diferente.

Embora muitos discursos sublinhem o fato de o pós-humanismo, na verdade, uma representação ainda mais radical de uma visão integral do

\footnotetext{
${ }^{7}$ Para maiores esclarecimentos sobre o dualismo platônico, ver a discussão sobre a matriz metafísica como invólucro da revelação (ROCHA, 2017, p. 974-996 [976-981]).

${ }^{8}$ Quanto a isso, destaca-se a importante coletânea organizada por Alfonso García Rúbio (2007).
} 
ser humano, já que propõe a hibridização do úmido biológico com a secura do silício, em certo sentido não se pode ignorar que o pós-humanismo também é um tipo de dualismo que se apresenta de uma forma significativamente nova. Afinal, o pós-humanismo também se coloca como um horizonte que questiona os limites da constituição biológica e questiona o pressuposto (progressista) de que o ser humano, individualmente pensado, é o seu próprio corpo. Todas as perspectivas - por enquanto no plano teórico - que se constroem sobre o pressuposto de que é possível isolar a consciência do corpo - o que significaria, também, poder fazê-la migrar de corpo -, colocam em xeque a ideia de que somos o nosso corpo.

Assim como a passagem da velha versão do dualismo platônico para essa compreensão mais progressista tem representado um enorme desafio à Teologia cristã, por conta dos enormes ajustes que supõe, o mesmo se dirá da passagem dessas versões mais progressistas para uma que supostamente se ajustasse aos pressupostos pós-humanistas, supondo, é claro, que a postura da Teologia fosse a de se readequar em face disso. Estaríamos diante da necessidade de abrir mão da integralidade do ser humano, algo que ainda não conseguimos realizar plenamente no âmbito do Cristianismo e da Teologia cristã? Ou seja, a sensação parece ser a de que embora as discussões em torno dessas questões antropológicas já estejam retornando por uma nova via, a Teologia ainda está com dificuldades de chegar ao ponto de retorno. Metaforicamente, é como se contemplássemos todas essas discussões passarem por nós no sentido contrário, enquanto nós ainda estamos indo.

\subsection{A questão da promoção da vida}

À despeito da obsessão por controlar, melhorar e promover a vida humana (BOSTROM, 2005; PORTER, 2004), bem como de todos os efeitos deletérios que o fundamentalismo tem provocado no Cristianismo e no modo de se fazer Teologia, sobretudo no Brasil, felizmente há movimentos cristãos e Teologias que têm se posicionado em favor da vida. Há um discurso crescente de que a educação teológica latino-americana "[...] necessita apontar para novas possibilidades da vida humana, superando a competição entre os grupos religiosos. Necessita apontar para novas possibilidades hermenêuticas, atentas às dores e às alegrias, buscando redescobrir o humano no ser humano, seja mulher ou homem", afinal, é na relação com o outro que se descobre a beleza do inacabamento humano (ROCHA; ULRICH, 2018, p. 34-35) - nas palavras de Paulo Freire, “Onde há vida, há inacabamento" (1996, p. 55).

É rica a tradição que tem se construído no horizonte de uma Teologia humanizada, que se coloque à serviço da promoção da vida. Quanto a isso não se podem negar as contribuições da chamada "Reviravolta Antropológica" na Teologia Católica, em meados do século XX, que contou, por exemplo, 
com teólogos do calibre de Karl Rahner e Edward Schillebeeckx. Esse movimento, que se caracterizou por destacar o problema da relação entre história e dogma e entre crítica científica e Teologia (GIBELLINI, 2002, p. 153), destacou de forma significativa o âmbito da realização humana nas construções teológicas. Também a Teologia da Libertação e as Teologias Contextuais que daí derivaram, destacam-se por serem Teologias amplamente comprometidas com a libertação humana e promoção da vida.

Portanto, uma bandeira hasteada por vertentes mais progressistas do Cristianismo e por vertentes mais progressistas da Teologia cristã é a promoção da vida e, quanto a isso, não se poderia discordar de forma alguma. Entretanto, a militância em favor da vida, conquanto pareça se legitimar por si só, não deveria desconsiderar a importância da reflexão em torno dos seus limites, em torno do que, de fato, significa a vida. Isso que parece óbvio quando se luta em seu favor, torna-se extremamente complexo sempre que é discutido no contexto dessas biotecnologias futuristas que desafiam os seus limites, já que as discussões pós-humanistas colocam em xeque todos os conceitos tradicionais de vida que até hoje foram construídos. Os limites da vida tendem a ser cada vez mais questionados, a exemplo de uma recente discussão travada em torno da possibilidade e dos limites éticos e jurídicos da manipulação de células-tronco, levada a efeito há alguns anos aqui no Brasil. Embora essa seja uma questão-limite, que exigiria certa interdisciplinaridade em função de envolver não só a ciência, mas, também, a religião e o direito, na maior parte das vezes a discussão se polarizou, na medida em que cada uma das partes envolvidas tendia à absolutização de sua área de competência. Os representantes da ciência acreditavam se tratar de um assunto que deveria se encerrar nos limites da própria ciência; os representantes do direito acreditavam que de nada adiantava uma discussão se aquele conjunto de práticas não fosse legalmente regulamentado; os representantes da religião, por sua vez, transformaram a questão da sacralidade da vida em seu principal argumento. Mas, uma das principais questões envolvidas nas discussões foi o conceito de vida: o que é a vida? O que é a vida humana? É eticamente plausível manipular aquilo que já se constitui vida humana? Quando começa a vida humana? Quais os seus limites? E o que dizer das instâncias pré-humanas, mas que, no entanto, também são dotadas de vida? $\mathrm{Na}$ ocasião, todas as discussões pareceram tropeçar nessas questões.

A vida, em sua perspectiva tradicional, em geral foi pensada como algo que se compõe de estruturas bio-físico-químicas e também de algo mais: um elemento de fora, não manipulável, algo imponderável, em relação ao qual a ciência não se interessou, na maioria das vezes. Essa zona do imponderável, que sempre alimentou as narrativas religiosas, foi de alguma forma loteada pelo discurso religioso no passado. O que acontece atualmente é que a ciência, sobretudo essa que trabalha no horizonte que possibilita as tecnologias do pós-humano, tem se instalado cada vez mais nesse espaço que outrora era ocupado apenas pela religião. Numa 
perspectiva pós-humana, a prerrogativa de uma ciência que colonizou o espaço do imponderável passa a ser a de definir os rumos da evolução no futuro, tornando os seres humanos sujeitos do seu próprio destino.

Mesmo a ala mais progressista do Cristianismo e da Teologia cristã é provocada neste momento a repensar o seu conceito de vida. De fato, a questão não é fácil, afinal, se não se chegou a um consenso em torno das discussões sobre as células-tronco, mesmo realizadas no contexto de compreensões ainda reféns de conceitos tradicionais sobre a vida, o que se dirá dessas mesmas discussões no contexto dos grandes desafios colocados pelo pós-humanismo? Então, a questão que se coloca é: num futuro próximo, as lutas e embates em favor da vida estarão, na realidade, promovendo o quê? A vida, em sua acepção biológica tradicional? A vida em sua hibridização com outras formas biológicas? A vida em sua hibridização com as máquinas? A vida em seu lócus corpóreo? A vida meramente cerebral? Ou a vida-consciência? E o que dizer da vida eterna? Como pensá-la em meio a essa ebulição de conceitos? Sem dúvida, não estamos lidando com questões fáceis, mas, estamos lidando com questões urgentes.

\subsection{A questão da mudança comportamental humana}

Outra importante agenda daquelas vertentes mais progressistas do Cristianismo e da Teologia cristã é a proposta de se trabalhar em prol da mudança social, da mudança do comportamento humano. Ou seja, trata-se da missão de transformar as pessoas em pessoas melhores, mais humanas, mais solidárias, mais tolerantes, mais dialógicas, mais respeitadoras do espaço do outro, mais comunitárias, etc. Manchado por tantos episódios de desserviço à humanidade, levados à efeito por narrativas históricas equivocadas, o Cristianismo tende a colocar em relevo suas maiores e melhores contribuições, inspiradas na figura de Jesus e materializadas na história em muitos momentos importantes, tais como nas contribuições sociais de Wesley e o movimento metodista do século XVIII ou mesmo na luta pelos direitos civis, levada à efeito por Martin Luther King, nos Estados Unidos. Também é desse patrimônio histórico que a Teologia cristã extrai a sua melhor abordagem, tais como nas várias modalidades da Teologia da Libertação, da Teologia da Missão Integral e nas inúmeras propostas teológicas que sustentam uma presença cidadã da religião na esfera pública.

Aqui também a Teologia se vê provocada pelas propostas pós-humanistas. Quanto a isso, digno de nota é o diagnóstico pós-humano do filósofo social Francis Fukuyama, em sua obra "Nosso Futuro Pós-humano: Consequências da Revolução da Biotecnologia". Assim se pronuncia Fukuyama:

Poderia ser que as ferramentas utilizadas pelos reformistas sociais do século $\mathrm{XX},-$ da socialização precoce das crianças e a psicanálise até a propaganda de agitação e os campos de trabalho forçado - foram cruas demais para alterar 
de maneira efetiva o substrato natural da conduta humana. Em duas gerações disporemos do conhecimento e da tecnologia que nos permitirá realizar aquilo que os engenheiros sociais não conseguiram. Nesse estágio, teremos encerrado definitivamente a história humana, porque teremos abolido os seres humanos enquanto tais. Então começará uma nova história para além do humano (2003, p. 36).

O que Fukyama parece sinalizar é a possível vitória dos engenheiros genéticos nas áreas onde os métodos de reformismo social fracassaram. Com métodos muito melhores do que aqueles que se fiam na domesticação disciplinar - se considerarmos os meios mais "bancários" ou mesmo no ensino da autonomia - se considerarmos os métodos mais libertacionistas - finalmente chegaríamos ao fim da miséria, dos problemas, da agressividade, da violência, do crime, etc. Ou seja, a reprogramação precisa e eficaz dos seres humanos tornariam obsoletos quaisquer tipos de reforma social; tornaria obsoleto um dos maiores legados da humanidade, a educação; tornaria obsoleta a solidariedade, a ideologia, a política, e toda essa obsolescência se daria em função da intervenção biológica permitida pelas tecnologias de ponta. Certamente esse seria um cenário incrivelmente diferente de tudo o que já experimentamos como civilização.

E o que se dirá do Cristianismo, das religiões em geral e da própria Teologia? Aparentemente, num cenário pós-humano qualquer proposta de uma religião ou de uma Teologia humanista perde inteiramente sua relevância, afinal, como indicamos acima, não precisaríamos mais desses artifícios para transformar pessoas em indivíduos melhores, mais solidários, mais tolerantes, mais dialógicos, mais respeitadores do espaço do outro e mais comunitários. Não haveriam mais prisões, nem escolas ou partidos políticos, a fome e a saúde não seriam mais contadas entre os principais problemas da humanidade e o preconceito racial não mais existiria. Será que num mundo pós-humano ainda precisaríamos de um Wesley ou de um Luther King? Se tal cenário se fizesse possível, as religiões e a própria Teologia teriam que lidar com uma desconcertante resposta a essa pergunta: precisaríamos apenas da engenharia genética! Diante da suposta irrelevância do caráter social e reformista da religião, espaços se abririam para formas alternativas de fundamentalismo religioso e teológico? É possível!

\section{Conclusão}

Tal como expõe Michel Henry, em seu livro “Encarnação: Uma Filosofia da Carne" (2014), assentado tanto em sua tradição quanto nas Escrituras, o Cristianismo dispõe de um legado de fundamental importância para a 
compreensão de uma salvação que se dá no âmbito do corpo. Embora muitas leituras dualistas formataram Teologias que compreenderam o corpo com sede do pecado - concepções que se estenderam até os nossos dias -, segundo Henry, elas não deveriam se fiar no movimento cristão dos primeiros séculos, já que este subverteu completamente o dualismo grego e também transcendentalismo judaico. Sem dúvida, resgatar essa religião que redescobre o corpo como o lugar da salvação, é tarefa urgente, afinal, como afirma Chemello, "O corpo pode ser um dos poucos lugares em que ainda existe espaço para o diálogo da religião com a ciência" (p. 253-273 [270]).

Mas, como afirmamos ao longo deste artigo, mesmo que a Teologia sustente o seu discurso nessa direção, ainda assim se encontra sob a provocação das propostas pós-humanistas. Depois de apresentarmos, em linhas gerais, a agenda pós-humanista nos seus mais distintos desdobramentos e perspectivas, propusemos três provocações pós-humanistas à Teologia cristã e ao próprio Cristianismo. Pelos motivos apresentados, deixamos de fora as perspectivas metafísicas e fundamentalistas e nos concentramos nisso que denominamos "perspectiva mais progressista" do Cristianismo e da Teologia cristã. Evidentemente, há outros elementos a partir dos quais tem se sustentado boa parte do discurso progressista da Teologia contemporânea, tais como a questão da liberdade e dos direitos humanos, a questão da vulnerabilidade humana, a questão do fim da história, da espiritualidade laica, etc. - questões que também demandariam uma análise frente à provocações pós-humanistas -, mas deixaremos isso para uma reflexão futura.

\section{Referências}

ARTAXO, P. Uma nova era geológica em nosso planeta: o Antropoceno. Revista USP, São Paulo, n. 103, p. 13-24, 2014.

BAUDRILLARD, J. A sociedade de consumo. Portugal: Edições 70, 2008.

BOSTROM, N. A history of transhumanist thought. Journal of Evolution and Technology, Hartford, v.14, n.1, p.1-25, 2005.

CHEMELLO, O. R. Antropologia pós-humana: diálogos entre teologia e tecnologia. Teocomunicação, Porto Alegre, v. 41, n. 2, p. 253-273, jul./dez. 2011.

COUTO SOUZA, E. Uma estética para corpos mutantes. In: COUTO SOUZA, E.; GOELLNER VILODRE, S. (Orgs.). Corpos mutantes: ensaios sobre novas (d)eficiências corporais. 2. ed. Porto Alegre: UFRGS, 2009. p. 43-56.

DIÁRIO CATARINENSE. Revolução microscópica: indústrias de diversos setores de Santa Catarina investem em nanotecnologia. Disponível em: https://bit.ly/2Nfg5Pf. Acesso em: 20 jun. 2018. 
DUQUE, J. M. Utopias neognósticas do pós-humano na cibercultura: para uma leitura filosófico-teológica. Perspectiva Teológica, Belo Horizonte, v. 48, n. 1, p. 163182, jan./abr. 2016.

DONALD, M. Origins of the modern mind: three stages in the evolution of culture and cognition. Cambridge, MA: Harvard University Press, 1991.

EXTROPY INSTITUTE. Disponível em: <www.extropy.org>. Acesso em: 09 out. 2018.

FAURE, Olivier. O olhar dos médicos. In: CORBIN, Alain (Org.). História do corpo: da Revolução à Grande Guerra. 4. ed. Petrópolis: Vozes, 2012.

FELINTO, E. A Comunicação dos Autômatos: sobre o Imaginário do Pós-Humanismo na Internet, Revista Galáxia, São Paulo, n. 11, p. 107-124, Jun. 2006.

FERRY, L. A revolução do amor: por uma espiritualidade laica. São Paulo: Objetiva, 2012.

Do amor: uma filosofia para o século XXI. Rio de Janeiro: DIFEL, 2013.

FREIRE, Paulo. Pedagogia da autonomia: saberes necessários à prática educativa. 9. ed. São Paulo: Paz e Terra, 1996.

FUKUYAMA, F. Nosso futuro pós-humano: consequências da revolução da biotecnologia. Rio de Janeiro: Rocco, 2003.

FUTURISM. For The First Time Ever, A Woman in China Was Cryogenically Frozen: But is the procedure actually viable? Here's what you need to know. Disponível em: $<$ https://bit.ly/2vQgwtB>. Acesso em: 20 jun. 2018.

GARCÍA-RUBIO, A. (Org.). O humano integrado: abordagens de antropologia teológica. 2. ed. Petrópolis: Vozes, 2007.

GIBELLINI, R. A teologia do século XX. 2. ed. São Paulo: Loyola, 2002.

GONZÁLEZ MELADO, Fermín Jesús. La ideología que nos viene. Transhumanismo (humanity+), p. 205-228, 2010. Disponível em: <https://bit.ly/2mfQjPr>. Acesso em: 20.06.2018.

HABERMAS, J. Teoria de la acción comunicativa. Madrid: Taurus, 1988. v. I e II. El discurso filosófico de la modernidad. Madri: Taurus, 1989.

HARAWAY, D. A Cyborg Manifesto: science, technology, and socialist-feminism in the Late Twentieth Century. In: Simians, cyborgs, and women: the reinvention of nature. New York: Routledge, 1985. p. 149-82.

HENRY, M. Encarnação: uma filosofia da carne. São Paulo: É Realizações, 2014.

LACROIX, X. O corpo reencontrado. Perspectiva Teológica, Belo Horizonte, v. 46, n. 129, p. 247-266, mai/ago. 2014.

MANDRESSI, R. Dissecações e anatomia. In: VIGARELLO, G. (Org.). História do corpo: da Renascença às Luzes. 5. ed. Petrópolis: Vozes, 2012.

MOULIN, A. M. O corpo diante da medicina. In: COURTINE, J-J. (Org.). História do corpo: as mutações do olhar, o século XX. 4. ed. Petrópolis: Vozes, 2011.

PEPPERELL, R. The Post-human Condition. Oxford: Intellect, 1995. 
PORTER, R. Das tripas coração. Rio de Janeiro: Record, 2004.

QUARESMA, A. Nanocaos e a responsabilidade global. São Paulo: Escriba, 2006.

. Nanotecnologias: Zênite ou Nadir? São Paulo: Escriba, 2010.

RICOEUR, P. Da Interpretação: ensaio sobre Freud. Rio de Janeiro: Imago, 1977.

ROCHA, A. S. O Deus que vem a nós: reflexões hermenêutico-teológicas da revelação desde cima e desde baixo. Horizonte, Belo Horizonte, v. 15, n. 47, p. 974-996, jul./set. 2017.

ROCHA, A. S.; ULRICH, C. B. A dessacralização da violência contra as mulheres no altar do patriarcado: reflexões a partir dos conceitos desejo mimético e bode expiatório em René Girard - desafios para a educação teológica latino-americana. REFLEXUS, Vitória, v. 12, n. 19, p. 15-38, 2018.

SANTAELLA, L. Culturas e artes do pós-humano: da cultura das mídias à cibercultura. São Paulo, Paulus, 2003.

. Corpo e comunicação: sintoma da cultura. São Paulo: Paulus, 2004.

SIBILIA, P. O Homem Pós-orgânico: corpo, subjetividade e tecnologias digitais. Rio de Janeiro: Relume-Dumará, 2002.

TORRES QUEIRUGA, A. Fim do cristianismo pré-moderno. São Paulo: Paulus, 2003.

Artigo submetido em 16.07.2018 e aprovado em 28.11.2018.

Abdruschim Schaeffer Rocha é pastor metodista, Doutor em Teologia pela Pontifícia Universidade Católica do Rio de Janeiro (PUC-RIO), Mestre em Teologia - Faculdades EST, é professor de Teologia no Programa de Pós-graduação (mestrado profissional) da Faculdade Unida de Vitória. Orcid.org/0000-0001-7702-8392. E-mail: abdo@faculdadeunida.com.br

Endereço: Rua Maria de Oliveira Maresguia, 101

Europa Tower, Torre Londres, apto. 2404

Praia de Itaparica

29102-245 Vila Velha - ES 